\title{
Correction to: Lazy Sundays: role of day of the week and reactivity on objectively measured physical activity in older people
}

Jochen Klenk ${ }^{1,2,3^{*}}$, Raphael Simon Peter ${ }^{1}$, Kilian Rapp ${ }^{2}$, Dhayana Dallmeier ${ }^{4}$, Dietrich Rothenbacher ${ }^{1}$, Michael Denkinger ${ }^{4}$, Gisela Büchele ${ }^{1}$ and the ActiFE Study Group

\section{Correction to: Eur Rev Aging Phys Act (2019) 16:18 https://doi.org/10.1186/s11556-019-0226-1}

Following publication of the original article [1], the authors reported an error in the author list. The study group has been listed with the authors in the pdf version. The original article has been corrected. The correct presentation of the authors is shown below.

Jochen Klenk, Raphael Simon Peter, Kilian Rapp, Dhayana Dallmeier, Dietrich Rothenbacher, Michael Denkinger, Gisela Büchele, the ActiFE Study Group.

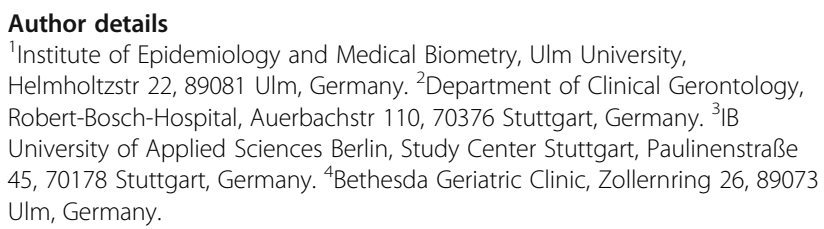

Published online: 05 December 2019

\section{Reference}

1. Klenk, et al. Lazy Sundays: role of day of the week and reactivity on objectively measured physical activity in older people. Eur Rev Aging Phys Act. 2019;16:18. https://doi.org/10.1186/s11556-019-0226-1.

\footnotetext{
The original article can be found online at https://doi.org/10.1186/s11556019-0226-1

*Correspondence: jochen.klenk@uni-ulm.de

'Institute of Epidemiology and Medical Biometry, Ulm University,

Helmholtzstr 22, 89081 Ulm, Germany

${ }^{2}$ Department of Clinical Gerontology, Robert-Bosch-Hospital, Auerbachstr 110,

70376 Stuttgart, Germany

Full list of author information is available at the end of the article
}

C The Author(s). 2019 Open Access This article is distributed under the terms of the Creative Commons Attribution 4.0 International License (http://creativecommons.org/licenses/by/4.0/), which permits unrestricted use, distribution, and reproduction in any medium, provided you give appropriate credit to the original author(s) and the source, provide a link to the Creative Commons license, and indicate if changes were made. The Creative Commons Public Domain Dedication waiver (http://creativecommons.org/publicdomain/zero/1.0/) applies to the data made available in this article, unless otherwise stated. 